\title{
Susceptibility Analysis of COVID-19 in Smokers Based on ACE2
}

\author{
Jin Wang ${ }^{1}$, Qiulin Luo ${ }^{1}$, Rui Chen ${ }^{2}$, Tao Chen ${ }^{1}$ and Jian-xiang $\mathrm{Li}^{1 *}$ \\ 1 Department of Toxicology, School of Public Health, Medicine College, Soochow University, Suzhou, \\ 215123, China. \\ 2 Department of Respiratory Medicine, The Second Affiliated Hospital of Soochow University, Suzhou, \\ 215004, China; \\ * Correspondence: aljxcr@suda.edu.cn; Tel.: +86-0512-65881038
}

\begin{abstract}
Background: Cigarette smoking (CS) is a global public health problem and a high-risk factor for various diseases. In December 2019, a novel coronavirus (COVID-19) was identified in Wuhan, China. Because ACE2 has been identified as a receptor for COVID-19, we hypothesize that CS affects the expression pattern of ACE2 in respiratory tract, causing differences in susceptibility to the virus. Methods: Three datasets (GSE994, GSE17913, and GSE18344), were downloaded from the Gene Expression Omnibus (GEO) database. Correlation and enrichment analysis were used to evaluate the function of ACE2. Also, the different expression of ACE2 in different groups of three datasets were analyzed. Results: Genes associated with ACE2 were enriched in important biological processes such as viral processes and immune response. Elevated ACE2 were found in intrapulmonary airways (GSE994) and oral epithelial cells (GSE17913) of smokers but not those of non-smokers or former smokers. Significant dose- and time-dependent relationships between CS and ACE2 expression were observed in mouse lung tissues, and long periods without smoking were found to significantly reduce ACE2 expression. Conclusions: Both human and rat data confirmed that CS could induce increased ACE2 in the respiratory tract, indicating that smokers have a higher susceptibility to COVID-19.
\end{abstract}

Keywords: Cigarette smoke; ACE2; COVID-19; susceptibility

\section{Introduction}

Cigarette smoking is a global public health problem. There are about 1.3 billion smokers in the world, and about one third of them live in China, which directly threatens the health of smokers and passive smokers [1]. The health problems caused by smoking are a hot issue of public concern, but it is still difficult to solve because it involves personal living habits. Cigarette smoking can cause lung cancer and cardiovascular and reproductive system problems [2]. Studies have demonstrated that smokers are susceptible to Middle East Respiratory Syndrome Coronavirus (MERS-CoV) [3].

Coronaviruses can infect humans, various birds, and mammals worldwide. In February and March 2003 there were major outbreaks of Severe Acute Respiratory Syndrome (SARS) in many countries. As of July 31, 2003, 8098 probable cases were reported, with a death toll of $774(9.6 \%)$ [4]. Between March 2012 and November 2015, MERS broke out in several countries, including Saudi Arabia (1255 cases and 539 deaths), South Korea (185 cases and 36 deaths), and the United Arab Emirates (81 cases and 11 deaths) [5]. In December of 2019, a novel coronavirus (2019-nCov, COVID19) was identified in Wuhan, Hubei Province, China. As of February 23, 2020, COVID-19 has infected 77,262 people and caused 2595 deaths in China, with rapidly growing numbers of cases reported internationally. People of all ages can be infected by the new coronavirus (COVID-19). Elderly people and people with pre-existing diseases, such as asthma, diabetes, and heart disease seem to be more susceptible to the virus or have more severe symptoms [6]. There was also a significant gender 
difference in incidence with 0.31 (male) vs. 0.27 (female) patients per 100,000 people [7]. The difference might be caused by smoking behavior.

The COVID-19 genome is approximately $80 \%$ identical to SARS-CoV and approximately $96 \%$ identical to bat coronavirus [8]. Structural analyses have established atomic-level interactions between SARS-CoV spike glycoprotein (S protein) receptor-binding domain (RBD) and its receptor, angiotensin-converting enzyme 2 (ACE2), which contribute to the cross-species and human-tohuman transmissions of SARS-CoV $[9,10]$. It has been shown that the $S$ protein of COVID-19, which is the same as that of SARS-CoV, may exploit ACE2 for host infection [11-13]. One recent study suggests that the affinity between ACE2 and the RBD of COVID-19 is 10-20 times greater than that of SARS-CoV [13]. The level of expression of ACE2 may reflect the susceptibility to COVID-19.

In this study, we analyzed the patterns of expression of ACE2 in the respiratory tract tissues of humans and mice with different smoking states based on three Gene Expression Omnibus (GEO) datasets. We aimed to determine whether cigarette smoking is a susceptibility factor for COVID-19.

\section{Materials and Methods}

\subsection{Data source}

Three GEO datasets, GSE994, GSE17913, and GSE18344, were obtained from the GEO database (http://www.ncbi.nlm.nih.gov/geo). The samples in GSE994 were obtained from intrapulmonary airways from normal smoking and non-smoking volunteers (including 34 current smokers, 23 never smokers, and 18 former smokers). The overall design of GSE17913 involved oral biopsy from 40 current smokers and 40 age- and gender-matched never smokers. We also extracted 55 samples from 14 different groups in the GSE18344 dataset, including a sham group (sham) and exposure group. The mice in the exposure group were continuously exposed to cigarette smoke (CS, $750 \mu \mathrm{g}$ total particulate matter/L) for 2, 3, or $4 \mathrm{~h}$ /day (our low, medium, and high dose groups, respectively). Exposure time included 1 day, 2 months, and 5 months, as well as 5 months +1 day recovery and 5 months +13 days recovery (medium dose only). There were four replicates for each group in GSE18344.

\subsection{Correlation and enrichment analysis}

R software was used to identify and import the list of genes correlated with ACE2 in the GSE994 and GSE17913 datasets. These related genes were then imported into the DAVID online tool for Gene Oncology (GO) enrichment analysis.

\subsection{Analysis of ACE2 expression in patients with different smoking histories}

All samples in the GSE994 and GSE17913 datasets were grouped according to smoking history. GSE994 was divided into three groups, including (1) never smokers (never), (2) current smokers (current), and (3) former smokers (former); GSE17913 was divided into two groups including (1) never smokers (never) and (2) current smokers (current). Changes in ACE2 expression were evaluated between groups in the datasets.

\subsection{Statistical analyses and plots}

In the correlation analysis, genes with a $\mid$ correlation coefficient $\mid>0.3$ and $P<0.05$ were considered significantly related genes. The t-test in GraphPad Prism 7 software was used to analyze the correlation between smoking history and ACE2 gene expression in the GSE994 and GSE17913 datasets and the differences in gene expression between different treatment groups in the GSE18344 dataset. $P<0.05$ is considered statistically significant

\section{Results}




\subsection{Functional enrichment of ACE2-related genes}

A total of 1370 positively and 1871 negatively ACE2-related genes were identified in the GSE994 intrapulmonary airway dataset, and 544 positively and 182 negatively related genes were found in the GSE17913 oral epithelial cell dataset (Table 1, 2). The genes in GSE994 were significantly enriched in essential biological processes including cell-cell adhesion, viral processes, viral transcription, intracellular transport of viruses, and the TGF- $\beta$ receptor signaling pathway (Figure 1A). In GSE17913, the genes were significantly enriched in biological processes including immune response, viral processes, $\mathrm{T}$ cell immunity, and apoptosis (Figure 1B).

Table 1 Summary of genes related to ACE2 expression in two datasets

\begin{tabular}{ccc}
\hline Datasets & Positive & Negative \\
\hline GSE994 & 1370 & 1871 \\
GSE17913 & 544 & 182 \\
\hline
\end{tabular}

Table 2 Top 20 genes related to ACE2 expression in two datasets

\begin{tabular}{|c|c|c|c|c|c|}
\hline \multirow[b]{2}{*}{ Gene Symbol } & \multirow{2}{*}{$\begin{array}{c}\text { GSE994 } \\
\text { P value }\end{array}$} & \multirow[b]{2}{*}{$\mathbf{R}$} & \multicolumn{2}{|c|}{ GSE17913 } & \multirow[b]{2}{*}{$\mathbf{R}$} \\
\hline & & & Gene Symbol & $P$ value & \\
\hline CBX3 & $6.45 \mathrm{E}-11$ & 0.667 & SECTM1 & $1.71 \mathrm{E}-08$ & 0.583 \\
\hline РНКB & $1.34 \mathrm{E}-10$ & 0.659 & APOL1 & $4.28 \mathrm{E}-08$ & 0.570 \\
\hline PPP1CC & 4.16E-10 & 0.645 & CLPX & 6.65E-07 & 0.525 \\
\hline GOLGA7 & 5.83E-10 & 0.641 & RUNX3 & 7.65E-07 & 0.523 \\
\hline CDC123 & 1.50E-09 & 0.629 & BTN3A3 & $1.32 \mathrm{E}-06$ & 0.513 \\
\hline RAP1B & 2.32E-09 & 0.623 & EDC3 & $2.16 \mathrm{E}-06$ & 0.504 \\
\hline PPT1 & 4.17E-09 & 0.616 & PSMB9 & $8.02 \mathrm{E}-06$ & 0.479 \\
\hline PAIP1 & 8.23E-09 & 0.606 & TLCD2 & $9.34 \mathrm{E}-06$ & 0.476 \\
\hline TSPAN31 & $1.60 \mathrm{E}-08$ & 0.597 & MSRB1 & $9.74 \mathrm{E}-06$ & 0.475 \\
\hline CASP7 & $1.63 \mathrm{E}-08$ & 0.596 & S100A12 & $1.02 \mathrm{E}-05$ & 0.474 \\
\hline TM9SF3 & 2.05E-08 & 0.593 & CORO1A & $1.31 \mathrm{E}-05$ & 0.469 \\
\hline COPB1 & $2.09 \mathrm{E}-08$ & 0.593 & CEACAM7 & 0.000014 & 0.468 \\
\hline APOBEC3G & $2.15 \mathrm{E}-08$ & 0.592 & NKG7 & $1.62 \mathrm{E}-05$ & 0.464 \\
\hline CCDC6 & 2.33E-08 & 0.591 & TAP1 & $1.78 \mathrm{E}-05$ & 0.462 \\
\hline PSMD7 & 2.81E-08 & 0.589 & ITGAL & 2.17E-05 & 0.458 \\
\hline PARP1 & $3.14 \mathrm{E}-08$ & 0.587 & GZMB & 2.18E-05 & 0.458 \\
\hline $\mathrm{ADO}$ & $3.21 \mathrm{E}-08$ & 0.587 & CUX1 & $2.21 \mathrm{E}-05$ & 0.458 \\
\hline SAT1 & 3.35E-08 & 0.586 & ТTС39С & $2.59 \mathrm{E}-05$ & 0.454 \\
\hline THOC7 & $3.39 \mathrm{E}-08$ & 0.586 & PAOX & 2.91E-05 & 0.452 \\
\hline DERA & $4.53 \mathrm{E}-08$ & 0.581 & ATP10B & $3.29 \mathrm{E}-05$ & 0.449 \\
\hline SEPW1 & $1.10 \mathrm{E}-12$ & -0.709 & $\mathrm{C} 7$ & 7.17E-05 & -0.432 \\
\hline CRIP1 & $1.66 \mathrm{E}-12$ & -0.705 & BUB1 & $1.02 \mathrm{E}-04$ & -0.423 \\
\hline SCAMP4 & $2.59 \mathrm{E}-12$ & -0.701 & CHRM5 & $1.38 \mathrm{E}-04$ & -0.416 \\
\hline CNOT3 & $6.50 \mathrm{E}-12$ & -0.691 & RALA & $1.51 \mathrm{E}-04$ & -0.414 \\
\hline CLDN3 & 7.30E-12 & -0.690 & VPS29 & $1.56 \mathrm{E}-04$ & -0.413 \\
\hline STRN4 & $1.78 \mathrm{E}-11$ & -0.681 & CADM3-AS1 & $2.00 \mathrm{E}-04$ & -0.407 \\
\hline CABIN1 & $3.49 \mathrm{E}-11$ & -0.674 & KIAA1456 & $2.55 \mathrm{E}-04$ & -0.400 \\
\hline ITGA3 & $3.61 \mathrm{E}-11$ & -0.673 & LOC101929002 & 2.70E-04 & -0.399 \\
\hline MFSD10 & $4.01 \mathrm{E}-11$ & -0.672 & KIRREL3-AS2 & 3.13E-04 & -0.395 \\
\hline BAG6 & $4.89 \mathrm{E}-11$ & -0.670 & OR1I1 & $4.28 \mathrm{E}-04$ & -0.387 \\
\hline BDH1 & $9.34 \mathrm{E}-11$ & -0.663 & RAB4A & 4.32E-04 & -0.387 \\
\hline
\end{tabular}




\begin{tabular}{|c|c|c|}
\hline NPIPA1 & $9.88 \mathrm{E}-11$ & -0.662 \\
\hline ABHD11 & $1.89 \mathrm{E}-10$ & -0.655 \\
\hline CST3 & 2.20E-10 & -0.653 \\
\hline MED12 & 2.59E-10 & -0.651 \\
\hline RNH1 & 2.95E-10 & -0.649 \\
\hline MORN1 & 3.09E-10 & -0.649 \\
\hline TJP3 & 4.07E-10 & -0.645 \\
\hline PYY & 4.92E-10 & -0.643 \\
\hline GLB1L2 & $6.76 \mathrm{E}-10$ & -0.639 \\
\hline \multirow[t]{8}{*}{ A } & & GSE994 \\
\hline & \multirow{2}{*}{\multicolumn{2}{|c|}{$\begin{array}{r}\text { cell-cell adhesion } \\
\text { viral process }\end{array}$}} \\
\hline & & \\
\hline & \multicolumn{2}{|c|}{$\begin{array}{r}\text { viral process } \\
\text { intracellular protein transport }\end{array}$} \\
\hline & \multicolumn{2}{|c|}{$\begin{array}{l}\text { Intraceliular protein transport } \\
\text { cell division }\end{array}$} \\
\hline & \multicolumn{2}{|c|}{ viral transcription - } \\
\hline & \multicolumn{2}{|c|}{ intracellular transport of virus - } \\
\hline & \multicolumn{2}{|c|}{ TGF- $\beta$ receptor signaling pathway -} \\
\hline \multicolumn{3}{|c|}{ positive regulation of viral genome replication - } \\
\hline \multicolumn{3}{|c|}{ negative regulation of EGF receptor signaling pathway } \\
\hline \multicolumn{3}{|c|}{ negative regulation of viral release from host cell- } \\
\hline
\end{tabular}

$\begin{array}{ccc}\text { LOC200830 } & 4.40 \mathrm{E}-04 & -0.386 \\ \text { GRK5 } & 4.57 \mathrm{E}-04 & -0.385 \\ \text { RP11-214K3.19 } & 4.85 \mathrm{E}-04 & -0.384 \\ \text { ANXA2 } & 5.36 \mathrm{E}-04 & -0.381 \\ \text { RP11-354I10.1 } & 6.03 \mathrm{E}-04 & -0.378 \\ \text { AGAP11 } & 6.27 \mathrm{E}-04 & -0.376 \\ \text { ZNF582-AS1 } & 6.54 \mathrm{E}-04 & -0.375 \\ \text { FKSG49 } & 6.63 \mathrm{E}-04 & -0.375 \\ \text { PEG3 } & 6.75 \mathrm{E}-04 & -0.374\end{array}$

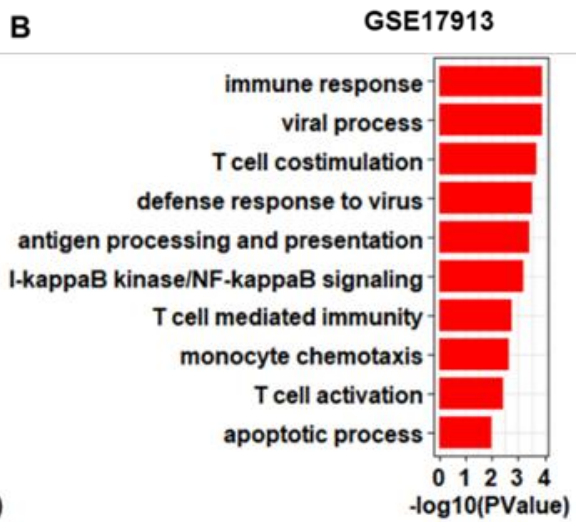

Figure 1. Histogram of Gene Ontology enrichment analysis of genes associated with ACE2 expression in the (A) GSE994 and (B) GSE17913 datasets.

\subsection{ACE2 expression and correlation with smoking history}

In the GSE994 intrapulmonary airway dataset, the level of expression of ACE2 in current smokers is significantly higher than that in never smokers $(\mathrm{t}=2.295, P=0.026)$ (Figure 2A). There was no significant difference between never smokers and reformed smokers. In addition, the ACE2 expression level was much lower in reformed smokers than in current smokers $(t=2.709, P=0.001)$ (Figure 2A). In the GSE17913 oral epithelial cell dataset, the level of expression of ACE2 in current smokers was significantly higher than in never smokers $(t=3.674, P<0.001)$ (Figure 2B).

A

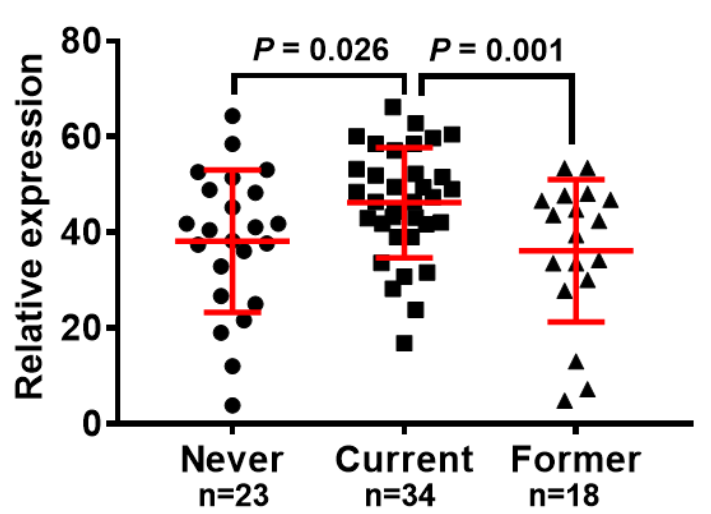

B

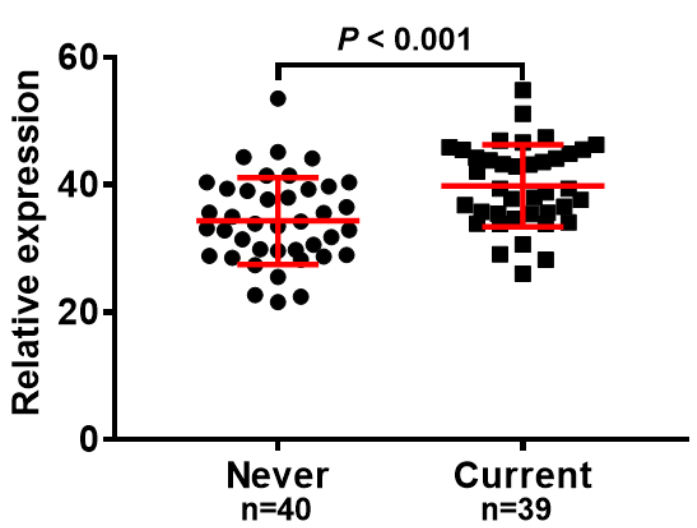

Figure 2. ACE2 expression levels in volunteers with different smoking history in the (A) GSE994 and (B) GSE17913 datasets. 
After 1 day of CS treatment, the level of expression of ACE2 in the medium CS-exposed group was significantly downregulated relative to the control group (Figure 3A) However, ACE2 expression level was significantly higher in the medium CS-exposed group after 2 and 5 months of treatment (Figure 3A). After 5 months of CS exposure, ACE2 expression levels in the medium- and high-dose groups were upregulated in a dose-dependent manner (Figure 3B). A significant dosedependent increase in ACE2 expression was also observed in the lungs of mice exposed to 5 months CS plus 1 day recovery (Figure 3C). In addition, the ACE2 expression level was higher in the mediumdose group after 5 months CS treatment plus 13 days of recovery (Figure 3D).

A

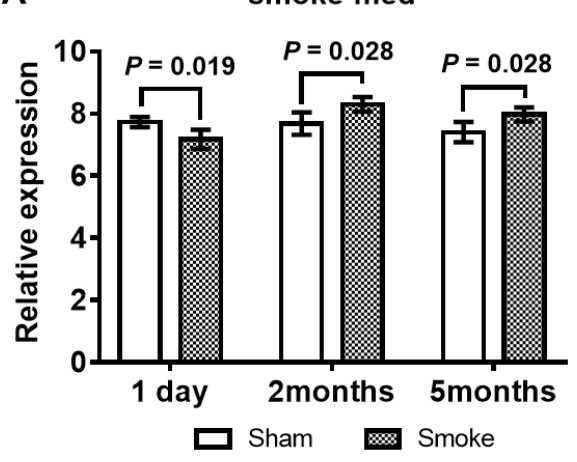

C

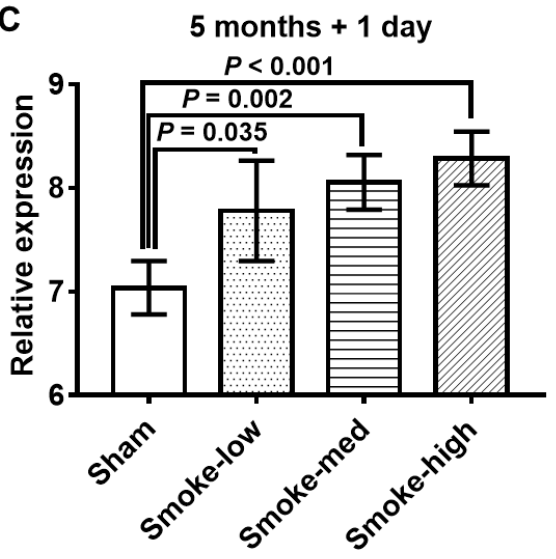

B

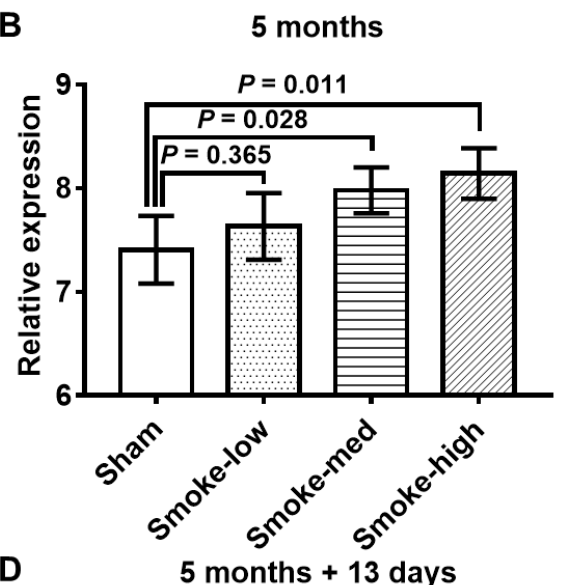

D

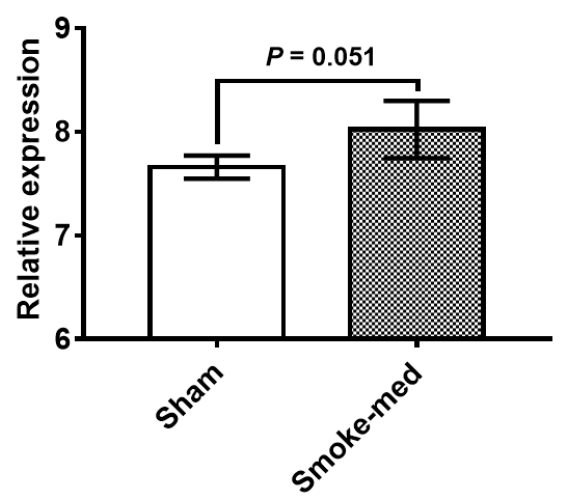

Figure 3. Data analysis of smoking-exposed mouse model. (A) ACE2 expression levels measured at different times after medium smoking (smoke-med) exposure; (B) ACE2 expression levels in different dose groups after 5 months of smoking exposure; (C) ACE2 expression levels in different dose groups after 5 months of smoking exposure and 1 day of recovery; (D) ACE2 expression level in the smokemed group after 5 months of smoking exposure and 13 days of recovery.

\section{Discussion}

Studies have established that ACE2 is the receptor for the SARS-CoV $[9,10]$ and Wuhan new coronavirus (COVID-19) [11-13]. Based on correlation and enrichment analysis of two human datasets (GSE994 and GSE17913), we found smoke-induced changes in ACE2 expression to be correlated with essential biological processes including viral processes and immune response, indicating that ACE2 is involved in virus infection and immune response.

Studies of the SARS epidemic from 2002 to 2003 have shown that people under the age of 25 have mild or moderate symptoms, while those over 60 , with more serious illnesses, had a mortality rate of more than $50 \%$ [14]. Epidemiological studies also showed sex-specific differences in incidence and fatality rates for SARS-CoV infection [15,16]. For COVID-19, people at all ages can be infected but elderly people and people with pre-existing diseases showed high susceptibility [6]. There is also a clear sex-dependent incidence of this disease, with a higher incidence in men than in women, which may be due to the high rate of smoking among men [7]. 
It is well known that CS is a high risk factor to such diseases as cardiovascular disease, chronic obstructive pulmonary disease, and cancer [17]. Studies have confirmed the relationship between CS and the susceptibility of influenza infections [18]. In addition, CS affects platelet-activating factor metabolism and may contribute to the elevated incidence of bacterial superinfection in people who develop influenza [19]. Moreover, influenza antibodies decreased more rapidly in smokers than in nonsmokers [20]. Another study found that CS can damage the host's antiviral response, contributing to the increased rate of influenza infection and the incidence of lower respiratory tract disease in smokers [21]. In this study, elevated ACE2 expression was found in intrapulmonary airways and oral epithelial cells in smokers compared with non-smokers, indicating that smokers are susceptible to 2019-CoV. Importantly, the ACE2 expression level was lower in reformed smokers, suggesting that quitting smoking can reduce susceptibility to 2019-CoV. Animal experiments have also shown significant dose- and time-dependent relationships between CS exposure and ACE2 expression in the lung tissues of mice. Quitting smoking for a long time but not short time could reverse the overexpression of ACE2 in the lungs of mice.

\section{Conclusions}

In conclusion, our results indicated that CS could induce elevated ACE2 expression in the respiratory tract, indicating that smokers have a higher susceptibility to COVID-19 than non-smokers. Since CS-induced changes in ACE2 expression are associated with viral infection and immune processes, smokers infected with COVID-19 may have serious health problems. Further epidemiological data are needed to verify these findings.

Author Contributions: Conceptualization, T.C. and J.L.; methodology, J.W. and Q.L.; software, J.W.; writingoriginal draft preparation, J.W. and Q.L.; writing - review and editing, T.C., R.C. and J.L.; funding acquisition, R.C. and J.L. All authors have read and agreed to the published version of the manuscript.

Funding: This study was supported by the National Natural Science Foundation of China (81573178 and 81770085).

Acknowledgments: We thank LetPub (www.letpub.com) for its linguistic assistance during the preparation of this manuscript.

Conflicts of Interest: The authors declare no conflict of interest.

\section{References}

1. Zhang, H.; Cai, B. The impact of tobacco on lung health in China. Respirology 2003, 8, 17-21, doi:10.1046/j.1440-1843.2003.00433.x.

2. IARC. Tobacco smoke and involuntary smoking. IARC Monogr Eval Carcinog Risks Hum 2004, 83, 1-1438.

3. Alraddadi, B.M.; Watson, J.T.; Almarashi, A.; Abedi, G.R.; Turkistani, A.; Sadran, M.; Housa, A.; Almazroa, M.A.; Alraihan, N.; Banjar, A., et al. Risk Factors for Primary Middle East Respiratory Syndrome Coronavirus Illness in Humans, Saudi Arabia, 2014. Emerg Infect Dis 2016, 22, 49-55, doi:10.3201/eid2201.151340.

4. Hui, D.S.; Chan, M.C.; Wu, A.K.; Ng, P.C. Severe acute respiratory syndrome (SARS): epidemiology and clinical features. Postgrad Med J 2004, 80, 373-381, doi:10.1136/pgmj.2004.020263.

5. Kim, K.H.; Tandi, T.E.; Choi, J.W.; Moon, J.M.; Kim, M.S. Middle East respiratory syndrome coronavirus (MERS-CoV) outbreak in South Korea, 2015: epidemiology, characteristics and public health implications. J Hosp Infect 2017, 95, 207-213, doi:10.1016/j.jhin.2016.10.008.

6. Novel Coronavirus (2019-nCoV) advice for the public:Myth busters. Availabe online: https://www.who.int/emergencies/diseases/novel-coronavirus-2019/advice-for-public/myth-busters. (accessed on 2020.03.03). 
7. Yang, Y.; Lu, Q.; Liu, M.; Wang, Y.; Zhang, A.; Jalali, N.; Dean, N.; Longini, I.; Halloran, M.E.; Xu, B., et al. Epidemiological and clinical features of the 2019 novel coronavirus outbreak in China. 2020, 10.1101/2020.02.10.20021675 \%J medRxiv, 2020.2002.2010.20021675, doi:10.1101/2020.02.10.20021675 \%J medRxiv.

8. Zhou, P.; Yang, X.L.; Wang, X.G.; Hu, B.; Zhang, L.; Zhang, W.; Si, H.R.; Zhu, Y.; Li, B.; Huang, C.L., et al. A pneumonia outbreak associated with a new coronavirus of probable bat origin. Nature 2020, 10.1038/s41586-020-2012-7, doi:10.1038/s41586-020-2012-7.

9. He, L.; Ding, Y.; Zhang, Q.; Che, X.; He, Y.; Shen, H.; Wang, H.; Li, Z.; Zhao, L.; Geng, J., et al. Expression of elevated levels of pro-inflammatory cytokines in SARS-CoV-infected ACE2+ cells in SARS patients: relation to the acute lung injury and pathogenesis of SARS. J Pathol 2006, 210, 288-297, doi:10.1002/path.2067.

10. Li, W.; Sui, J.; Huang, I.C.; Kuhn, J.H.; Radoshitzky, S.R.; Marasco, W.A.; Choe, H.; Farzan, M. The S proteins of human coronavirus NL63 and severe acute respiratory syndrome coronavirus bind overlapping regions of ACE2. Virology 2007, 367, 367-374, doi:10.1016/j.virol.2007.04.035.

11. Zhou, P.; Yang, X.-L.; Wang, X.-G.; Hu, B.; Zhang, L.; Zhang, W.; Si, H.-R.; Zhu, Y.; Li, B.; Huang, C.-L., et al. A pneumonia outbreak associated with a new coronavirus of probable bat origin. Nature 2020, 10.1038/s41586-020-2012-7, doi:10.1038/s41586-020-2012-7.

12. Wan, Y.; Shang, J.; Graham, R.; Baric, R.S.; Li, F. Receptor recognition by novel coronavirus from Wuhan: An analysis based on decade-long structural studies of SARS. J Virol 2020, 10.1128/JVI.00127-20, doi:10.1128/JVI.00127-20.

13. Tian, X.; Li, C.; Huang, A.; Xia, S.; Lu, S.; Shi, Z.; Lu, L.; Jiang, S.; Yang, Z.; Wu, Y., et al. Potent binding of 2019 novel coronavirus spike protein by a SARS coronavirus-specific human monoclonal antibody. Emerg Microbes Infect 2020, 9, 382-385, doi:10.1080/22221751.2020.1729069.

14. Nicholls, J.M.; Poon, L.L.; Lee, K.C.; Ng, W.F.; Lai, S.T.; Leung, C.Y.; Chu, C.M.; Hui, P.K.; Mak, K.L.; Lim, W., et al. Lung pathology of fatal severe acute respiratory syndrome. Lancet 2003, 361, 1773-1778, doi:10.1016/s0140-6736(03)13413-7.

15. Karlberg, J.; Chong, D.S.Y.; Lai, W.Y.Y. Do men have a higher case fatality rate of severe acute respiratory syndrome than women do? American Journal of Epidemiology 2004, 159, 229-231, doi:10.1093/aje/kwh056.

16. Leong, H.N.; Earnest, A.; Lim, H.H.; Chin, C.F.; Tan, C.S.H.; Puhaindran, M.E.; Tan, A.C.H.; Chen, M.I.C.; Leo, Y.S. SARS in Singapore - Predictors of disease severity. Ann Acad Med Singap 2006, 35, 326331.

17. Courtney, R. The Health Consequences of Smoking-50 Years of Progress: A Report of the Surgeon General, 2014Us Department of Health and Human Services Atlanta, GA: Department of Health and Human Services, Centers for Disease Control and Prevention, National Center for Chronic Disease Prevention and Health Promotion, Office on Smoking and Health, 20141081 pp. Online (grey literature): http://www.surgeongeneral.gov/library/reports/50-years-of-progress. $\quad$ 2015， 34， 694-695, doi:10.1111/dar.12309.

18. Finklea, J.F.; Sandifer, S.H.; Smith, D.D. Cigarette smoking and epidemic influenza. Am J Epidemiol 1969, 90, 390-399, doi:10.1093/oxfordjournals.aje.a121084.

19. Miyaura, S.; Eguchi, H.; Johnston, J.M. Effect of a cigarette smoke extract on the metabolism of the proinflammatory autacoid, platelet-activating factor. Circ Res 1992, 70, 341-347, doi:10.1161/01.res.70.2.341. 
20. Finklea, J.F.; Hasselblad, V.; Riggan, W.B.; Nelson, W.C.; Hammer, D.I.; Newill, V.A. Cigarette smoking and hemagglutination inhibition response to influenza after natural disease and immunization. Am Rev Respir Dis 1971, 104, 368-376, doi:10.1164/arrd.1971.104.3.368.

21. Aronson, M.D.; Weiss, S.T.; Ben, R.L.; Komaroff, A.L. Association between cigarette smoking and acute respiratory tract illness in young adults. Jama 1982, 248, 181-183. 